\title{
Structural phase evolution with temperature of non-conventional particles in PIM
}

\author{
F.M. Barreiros ${ }^{a, b, *}$, M.T. Vieira ${ }^{b}$ \\ a Departamento de Engenharia Mecânica, Escola Superior de Tecnologia e Gestão, Instituto Politécnico de Leiria, Campus 2, \\ Morro do Lena, Alto Vieiro, Apartado 4163, 2411-901 Leiria, Portugal \\ b ICEMS (Grupo de Materiais, Departamento de Engenharia Mecânica, Faculdade de Ciências e Tecnologia, Universidade de Coimbra), \\ Pinhal de Marrocos, Polo II, 3030-201 Coimbra, Portugal
}

\section{A R T I C L E I N F O}

Article history:

Received 11 August 2006

Received in revised form

17 July 2007

Accepted 3 August 2007

\section{Keywords:}

Inorganic natural powder

Phase transformations

Calcination

Feedstock

Powder injection moulding

Mechanical properties

\begin{abstract}
A B S T R A C T
Some inorganic natural powders may be interesting to manufacture complex shapes by powder injection moulding (PIM). However, these powders may evolve chemical and physically with temperature during the manufacturing processes, inducing blusters and geometrical irregularities, particularly loss of circularity. These imperfections were associated to gas liberation and dimensional variations during the debinding and sintering treatments and not to feedstocks' fluidity. Natural powders for manufacturing products by PIM must be previously calcined before conformation, in order to eliminate possible chemical reactions and phase transformation during debinding and sintering. To highlight the effect of the calcination process in the final quality of the sinter, a complex geometrical testing-probe was developed. After sintering, calcined and non-calcined powders have similar mechanical properties $\left(\sigma_{0}^{\text {calcined }}=111 \mathrm{MPa}, \sigma_{0}^{\text {non-calcined }}=93 \mathrm{MPa}\right.$, Weibull modulus $\left.=10\right)$. The use of a feedstock of the natural calcined powders leads to PIM products with high geometrical reproducibility and good surface finishing.
\end{abstract}

@ 2007 Elsevier B.V. All rights reserved.

\section{Introduction}

Powder injection moulding (PIM) is an attractive manufacturing process, which is widely used in industry to produce complex shapes for applications that require high performance and dimensional precision. The powder is blended with the minimum content of binder to obtain a homogeneous feedstock with appropriate rheological properties for powder injection moulding (Mutsuddy and Ford, 1995; German and Bose, 1997). Thus, a key factor for a successful production of parts via PIM is the feedstock quality, which requires an optimal powder content, homogeneity, good moldability, good response to debinding, and controlled shrinkage. These requirements are usually attained using synthetic raw materials with controlled morphology and particle size. However, there are other types of materials, namely natural raw materials (Haupt, 1996; Barreiros and Vieira, 2000; Barreiros et al., 2000; Agote et al., 2001; Barreiros et al., 2002), which can be an alternative source for PIM market. The main disadvantage of natural raw materials is they are chemically unstable and undergo phase evolution during debinding and sintering. Therefore, it affects the surface finishing of the final product for technical applications (Barreiros and Vieira, 2006).

The limitation of the natural raw materials usage in PIM can be resolved if the chemical reactions and physical transformations with temperature are irreversible. Thus, the aim

\footnotetext{
* Corresponding author at: Departamento de Engenharia Mecânica, Escola Superior de Tecnologia e Gestão, Instituto Politécnico de Leiria, Campus 2, Morro do Lena, Alto Vieiro, Apartado 4163, 2411-901 Leiria, Portugal. Tel.: +351 244 820300; fax: +351 244820310.

E-mail address: fbarreiros@estg.ipleiria.pt (F.M. Barreiros). 
of this study is to demonstrate the effect of heat treatment to modify the limitation of natural raw materials to obtain good quality products via PIM.

\section{Materials and experimental details}

\subsection{Materials}

In this research, an inorganic natural powder resulting from cutting and polishing operations of ornamental dimensional stones was calcined at $1170^{\circ} \mathrm{C}$ for half an hour prior to PIM process. After calcination, the powder was milled $(200 \mathrm{rpm}$ for $2 \mathrm{~h}$ ) and sieved $(\mathrm{d}<45 \mu \mathrm{m})$. The chemical composition of the calcined powder is similar to the natural powder (noncalcined powder), namely $\mathrm{SiO}_{2}=54 \%, \mathrm{Al}_{2} \mathrm{O}_{3}=24 \%$ and other oxides $\approx 20 \%$ (Barreiros and Vieira, 2000; Barreiros et al., 2000; Barreiros et al., 2002; Barreiros and Vieira, 2006). The physical characteristics of the calcined powder were evaluated based on the surface area (BET technique-Micromeritics ASAP 2000), the true density (Micromeritics Accupyc 1330 helium picnometer) and the tap density (vibration method). The mineralogical composition of the calcined powder was identified by X-ray diffraction (Philips model Xpert). The shape of the powder was observed by scanning electron microscopy (JEOL, JSM-5310) whereas particle size and particle size distribution of the powder were evaluated by laser diffraction (Coulter LS 130).

A commercial polymeric mixture based on polyolefin waxes (manufactured by Höechst) was used as binder.

\subsection{Experimental details}

\subsubsection{Feedstock preparation}

The critical powder volume concentration (CPVC) of the calcined powder was estimated by torque rheometry by monitoring the torque variation during the mixing of the calcined powder with the commercial binder, using a Brabender Plastograph mixer. The methodology adopted was described in previous works (Barreiros and Vieira, 2000; Barreiros et al., 2000; Barreiros and Vieira, 2006). Tests with powder contents varying between 61 and 68 vol.\% were performed using a preprogrammed temperature of $140^{\circ} \mathrm{C}$, a speed rotation of $60 \mathrm{rpm}$ and a mixing time of $20 \mathrm{~min}$.

A calcined feedstock containing $63 \%$ of powder was prepared using a combination of two mixers: plastograph mixer and single screw extruder (Brabender Stand Alone Extruder E 19/25 D). Several batches with appropriate weights $\left( \pm 1 \times 10^{-7} \mathrm{~kg}\right)$ of powder and binder were previously prepared in the plastograph mixer at $140^{\circ} \mathrm{C}$ during $30 \mathrm{~min}$ at $60 \mathrm{rpm}$. These feedstocks were then extruded using a barrel temperature profile of $110 / 120 / 130 / 140^{\circ} \mathrm{C}$ and a screw rotation speed of $60 \mathrm{rpm}$. After extrusion, the feedstock was pelletised.

The true density of the prepared feedstock was measured to evaluate its homogeneity; at least three different tests were performed by helium picnometry.

\subsubsection{Feedstock processing}

2.2.2.1. Injection moulding. To evaluate some mechanical properties of the calcined powder feedstock, parallelepiped
Table 1 - Injection moulding conditions

\begin{tabular}{lll}
\hline Injection conditions & Bars & Complex parts \\
\hline Barrel temperature $\left({ }^{\circ} \mathrm{C}\right)$ & $130 / 150$ & $120 / 130 / 140 / 150$ \\
Nozzle temperature $\left({ }^{\circ} \mathrm{C}\right)$ & 160 & 160 \\
Mould temperature $\left({ }^{\circ} \mathrm{C}\right)$ & 40 & 40 \\
Injection pressure $(\mathrm{MPa})$ & 6.6 & 6 \\
Packing pressure $(\mathrm{MPa})$ & 3.1 & 2.5 \\
Injection time $(\mathrm{s})$ & 6 & 5 \\
Cooling time $(\mathrm{s})$ & 25 & 20 \\
\hline
\end{tabular}

bars $(92.40 \mathrm{~mm} \times 5.80 \mathrm{~mm} \times 3.80 \mathrm{~mm})$ were injection-moulded using an injection machine (Arburg model All Rounder 220/150 E). In addition, to evaluate the moldability of the calcined feedstock, a mould with a cavity designed and tested to produce a "quality standard" was used (Barreiros et al., 2002). This mould had truncated cone-geometry, a smooth core and a cavity with ribs with sharp edges. The mould also had circular open holes with different inside and outside diameters. After injection moulding (Engel EC 88 series TP), the complex parts had a wall thickness of $3.6 \mathrm{~mm}$. Table 1 summarises the injection parameters used in the manufacturing of parallelepiped bars and complex parts.

2.2.2.2. Debinding and sintering. Several samples (bars and complex parts) were debinded in dynamic air. The debinding cycle used for the binder removal was similar to that of non-calcined powder (Barreiros and Vieira, 2006): $0.4^{\circ} \mathrm{C} \mathrm{min}{ }^{-1}$ up to $150^{\circ} \mathrm{C}$, followed by $0.2^{\circ} \mathrm{C} \mathrm{min}^{-1}$ up to $190^{\circ} \mathrm{C}$ and, finally, $0.3^{\circ} \mathrm{C} \mathrm{min}{ }^{-1}$ up to $600^{\circ} \mathrm{C}$, and cooling in the furnace to room temperature.

After debinding the brown parts were sintered in static air by heating to $1170^{\circ} \mathrm{C}$ at $10^{\circ} \mathrm{C} \mathrm{min}^{-1}$ and held at this temperature during $30 \mathrm{~min}$. This was followed by cooling in the furnace to room temperature.

\subsubsection{Physical and mechanical properties}

The true and apparent densities of some sintered samples (bars and complex parts) were measured by helium picnometry and by water immersion using a sealant (Archimedes method), respectively. The sintered parallelepiped bars were also used for evaluating the dimensional variations and for mechanical tests of flexural strength. To estimate the shrinkage value and the tendency for anisotropy, the dimensional variations before and after sintering were measured. In addition, the dimensional variations were compared with those of the parts manufactured with non-calcined powder. The tests of mechanical properties were performed to estimate the quality of the calcined powder PIM products. For this purpose, the sintered bars were tested in a Gabbrieli CRAB 424 testing machine.

\section{Results and discussion}

\subsection{Powder characterisation}

The calcined powder presented a surface area of $1.47 \times 10^{3} \mathrm{~m}^{2} \mathrm{~kg}^{-1}$, a true density of $2800 \mathrm{~kg} \mathrm{~m}^{-3}$, and a tap density of $53.6 \%$ of theoretical density. The analysis of the mineralogical composition of both non-calcined and calcined 


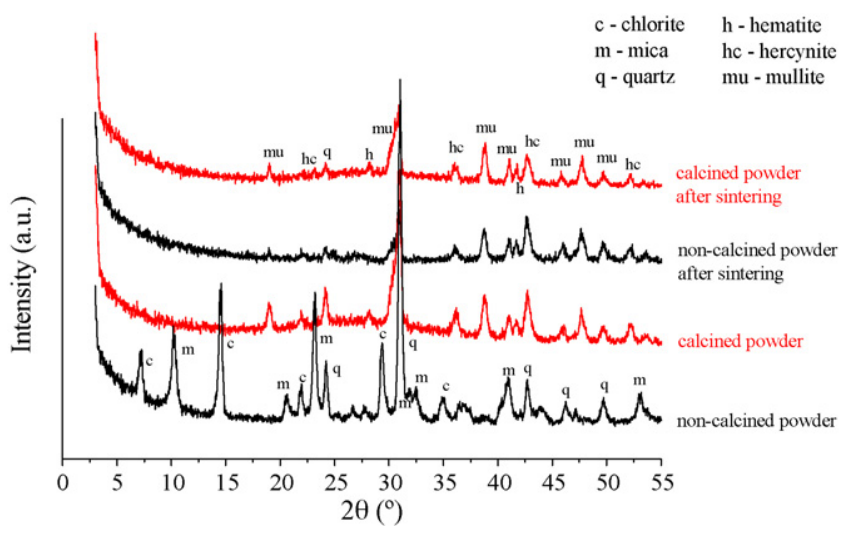

Fig. 1 - X-ray diffractograms of non-calcined and calcined powders before and after sintering.

powders (Fig. 1) allowed identifying the main constituents of the non-calcined powder - chlorite, mica and quartz - and of the calcined powder - mullite, quartz, hematite, hercynite and glassy phase. It is important to highlight that after sintering the mineralogical composition of the PIM products was the same of the calcined powder, independently of whether the powders were previously calcined or not (Fig. 1). The shape of the calcined and non-calcined powders is shown in Fig. 2(a) and (b), respectively. The calcined powder has an irregular shape while the non-calcined powder presents a lamellar shape. Both powders have a wide particle size distribution (Fig. 3), namely $0.1-70.32 \mu \mathrm{m}$ for calcined powder versus $0.1-174.8 \mu \mathrm{m}$ for non-calcined powder. The mean particle diameter $\left(d_{50}\right)$ of calcined powder was $6.10 \mu \mathrm{m}$ compared to $10.5 \mu \mathrm{m}$ of non-calcined powder. Besides the influence of calcination, these differences are mainly due to milling and sieving.

\subsection{Feedstock optimisation and preparation}

Fig. 4(a) and (b) depicts the results of the powder content optimisation. As described elsewhere (Barreiros and Vieira, 2000; Barreiros et al., 2000; Barreiros et al., 2002; Barreiros and Vieira, 2006), the mixing torque as a function of mixing time curves (Fig. 4(a)) denote two different rheological behaviours, depending on the powder content in the feedstock:

(a) Fast decrease of the mixing torque ( $\approx 10 \mathrm{~min})$ followed by the establishment of a steady state.

(b) Increase of the mixing torque followed by a decrease in the first minutes of the test, and attaining a constant mixing torque value after approximately $12 \mathrm{~min}$.

The critical powder volume concentration (CPVC) and the optimal powder concentration in the feedstock may be related to the transition between these two types of rheological behaviours. In fact, the more appropriate powder concentration in the calcined powder feedstock may correspond to the maximum value at which there is always a continuous decrease of the mixing torque with the mixing time (Barreiros and Vieira, 2000; Barreiros et al., 2000; Barreiros et al., 2002; Barreiros and Vieira, 2006). Thus, according to
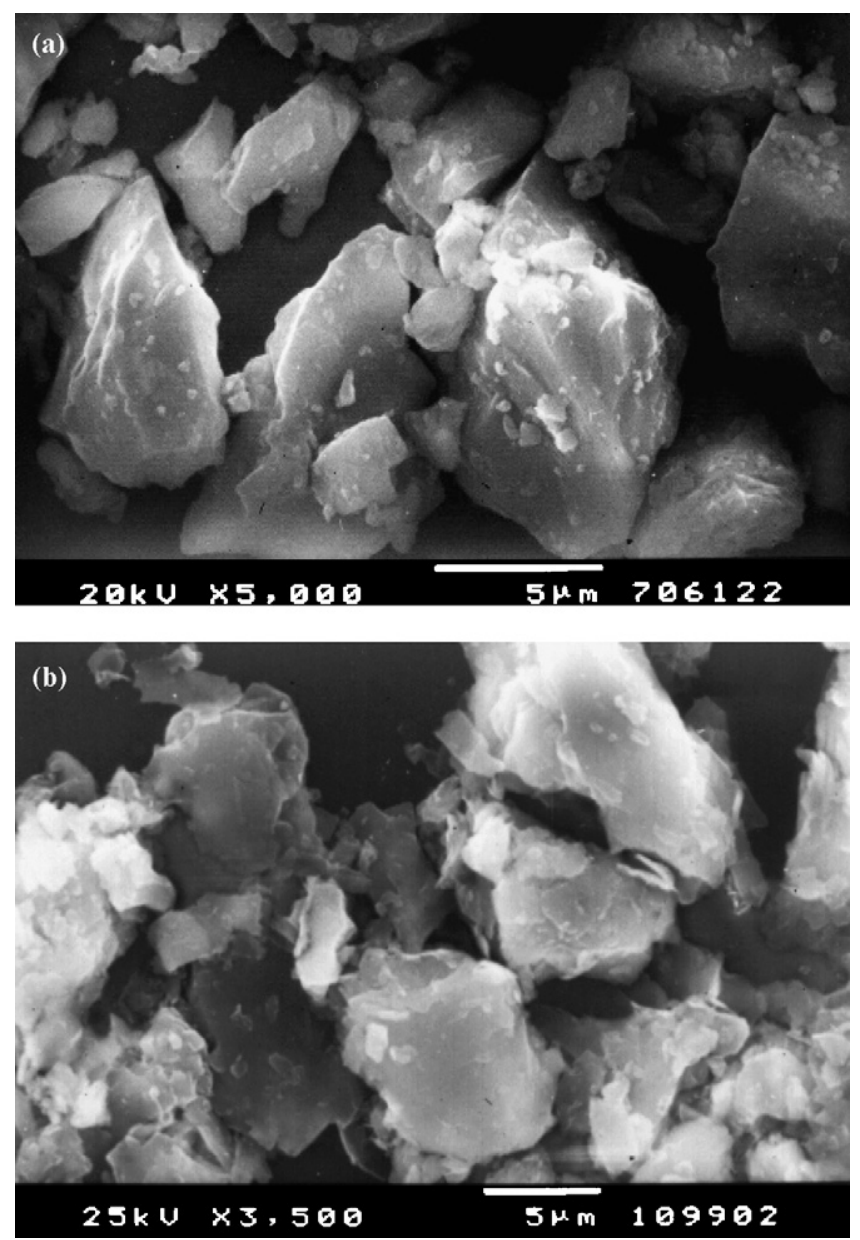

Fig. 2 - Particles morphology of calcined (a) and non-calcined powders (b).

Fig. 4(a), the CPVC value is about $64-65 \%$ and the optimal powder content $63 \%$, which is a very high value when compared to non-calcined powder feedstocks (59\%) (Barreiros and Vieira, 2006). Nevertheless, this increase of powder content can be attributed to the decrease of the mean particle size

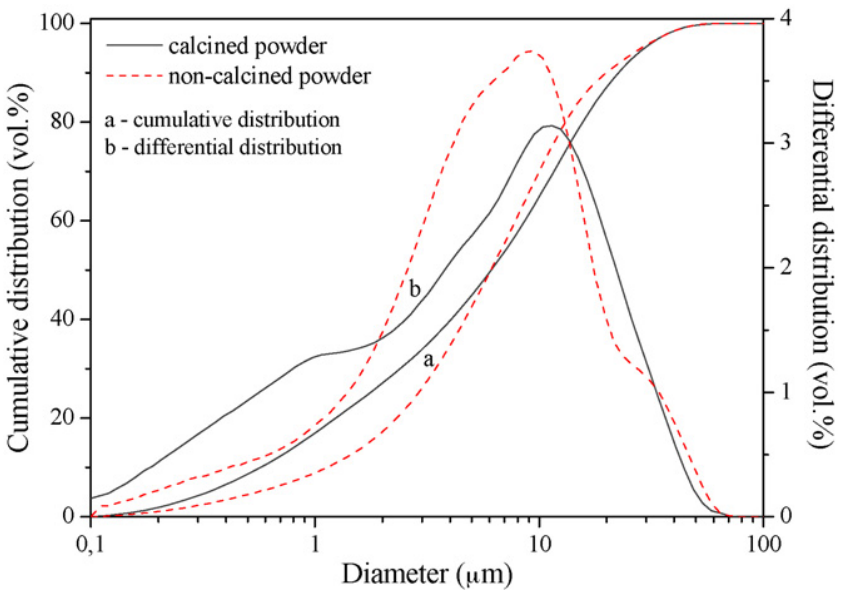

Fig. 3 - Particle size distribution of calcined and non-calcined powders. 

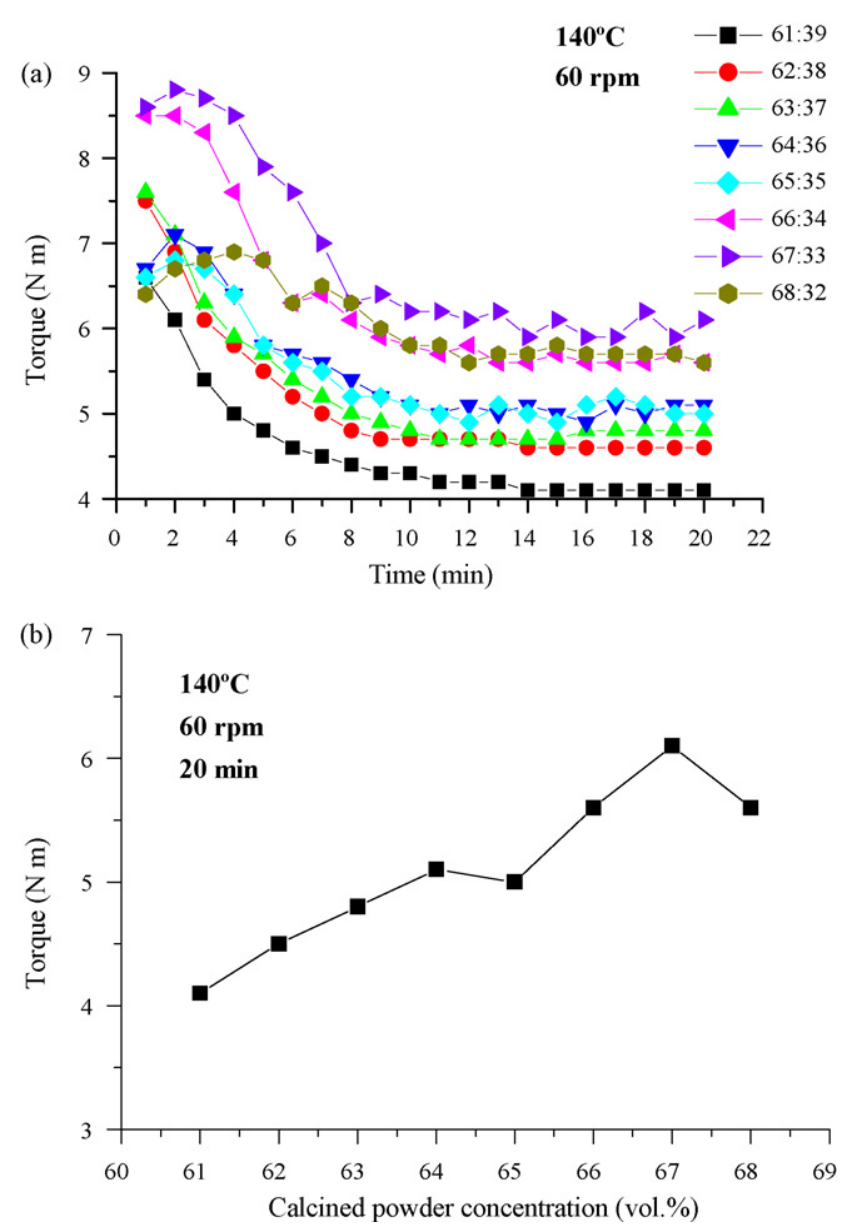

Fig. 4 - (a) Calcined powder mixing torque as a function of mixing time, at $60 \mathrm{rpm}$ and $140^{\circ} \mathrm{C}$; (b) Mixing torque as a function of calcined powder concentration.

of calcined powder due to the operations of milling and sieving.

Alternatively, the variation of the applied torque with the solids concentration after achieving a steady state $(t \cong 20 \mathrm{~min})$ allows comparing the rheological characteristics of different feedstocks when the effort for mixing is finished (Fig. 4(b)). When considering the relationship between the mixing torque and the powder concentration after attaining the steady state (Fig. 4(b)), four regimes may be identified. Initially, the mixing torque value increases gradually from 61 up to $64 \%$ of solids. After this point there is a slight decrease of the mixing torque, when the powder content reaches $65 \%$. This is followed by a significant increase up to $67 \%$ of solids. Finally, when the solids loading reaches $68 \%$, the torque value decreases that reflects

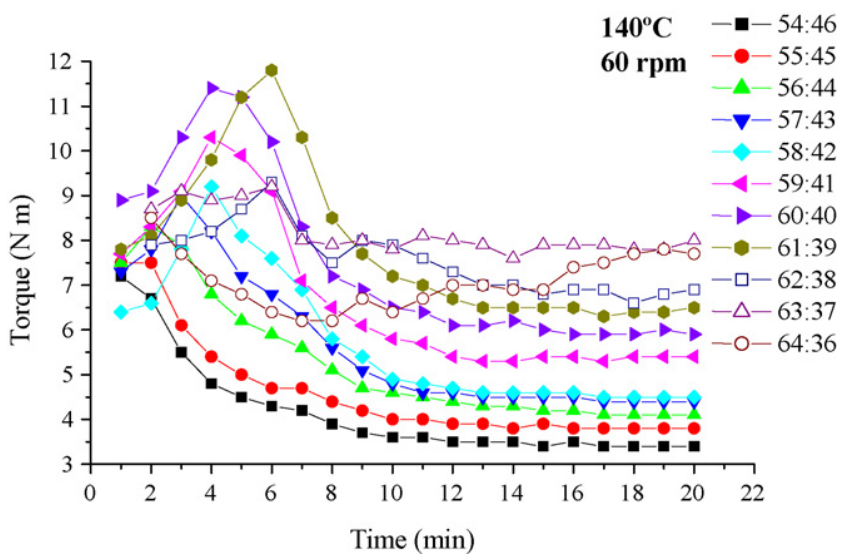

Fig. 5 - Non-calcined powder mixing torque as a function of mixing time, at $60 \mathrm{rpm}$ and $140^{\circ} \mathrm{C}$.

an excessive content of solids. Thus, the CPVC of the calcined powder feedstock may be close to $64-65 \%$ of solids because this value corresponds to an abrupt increase of the mixing torque with the increase of the solids content (Barreiros and Vieira, 2006). Considering that for the non-calcined powder the best results were obtained using a feedstock with a solids content slightly superior (59\%) to that predicted for CPVC (58\%) (Barreiros and Vieira, 2006), the optimal powder concentration in the calcined feedstock should be close to $64 \%$ of solids. However, for the calcined feedstocks the mixing torque becomes erratic for values in the order of $64 \%$ (Fig. 4(a)), in contrast to the observed for the non-calcined feedstock where the mixing torque was stable even for concentrations higher than the CPVC (Fig. 5) (Barreiros and Vieira, 2006). Therefore, the concentration of the calcined powder that was selected for the preparation of the feedstock to be injection-moulded was $63 \%$.

The average of the true density of the calcined feedstock and its standard deviation was $2150 \pm 1 \mathrm{~kg} \mathrm{~m}^{-3}$, and the theoretical density (mixtures law) was $2170 \mathrm{~kg} \mathrm{~m}^{-3}$. The proximity between both values of density and the low value of the standard deviation reveals a feedstock with excellent quality.

\subsection{Final products characterisation}

\subsubsection{Parallelepiped bars}

Table 2 shows some physical and mechanical characteristics of the calcined and non-calcined bars after sintering. The apparent $\left(\rho_{\text {apps }}\right)$ and true $\left(\rho_{\mathrm{s}}\right)$ densities values were similar due to the non-existence of open porosity, although the relationship between the apparent and the theoretical density

Table 2 - Physical and mechanical characteristics of the bars of calcined and non-calcined powders after sintering

\begin{tabular}{lcccccccc} 
Bars & $\rho_{\text {apps }}\left(\mathrm{kg} \mathrm{m}^{-3}\right)$ & $\rho_{\mathrm{s}}\left(\mathrm{kg} \mathrm{m}^{-3}\right)$ & $\mathrm{P}_{\text {total }}{ }^{\mathrm{a}}(\%)$ & $\sigma_{0}(\mathrm{MPa})$ & $m$ & $\Delta \mathrm{l} / \mathrm{l} \pm \sigma(\%)$ & $\Delta w / w \pm \sigma(\%)$ & $\Delta \mathrm{t} / \mathrm{t} \pm \sigma(\%)$ \\
\hline Calcined powder & $2570 \pm 10$ & $2570 \pm 1$ & $1.2 \pm 0.4$ & 111 & 10 & $11.98 \pm 0.06$ & $12.50 \pm 0.42$ & $13.10 \pm 0.27$ \\
Non-calcined powder & $2550 \pm 12$ & $2570 \pm 2$ & $1.9 \pm 0.5$ & 93 & 10 & $12.42 \pm 0.35$ & $13.27 \pm 0.57$ & $13.10 \pm 0.27$ \\
\hline
\end{tabular}


reveals close porosity $\left(P_{\text {total }}=1.2 \%\right)$. However, this value corresponds to a high value of densification (98.8\%) revealing the good performance of the calcined powder in the manufacturing of products by PIM, which is slightly superior to that using non-calcined powder (98.1\%) (Barreiros and Vieira, 2006).

Concerning the dimensional variations, the shrinkage values in the three directions, length $(l)$, width $(w)$ and thickness (t) were very similar among them and with non-calcined powder bars (Table 2) (Barreiros and Vieira, 2006).

(a)

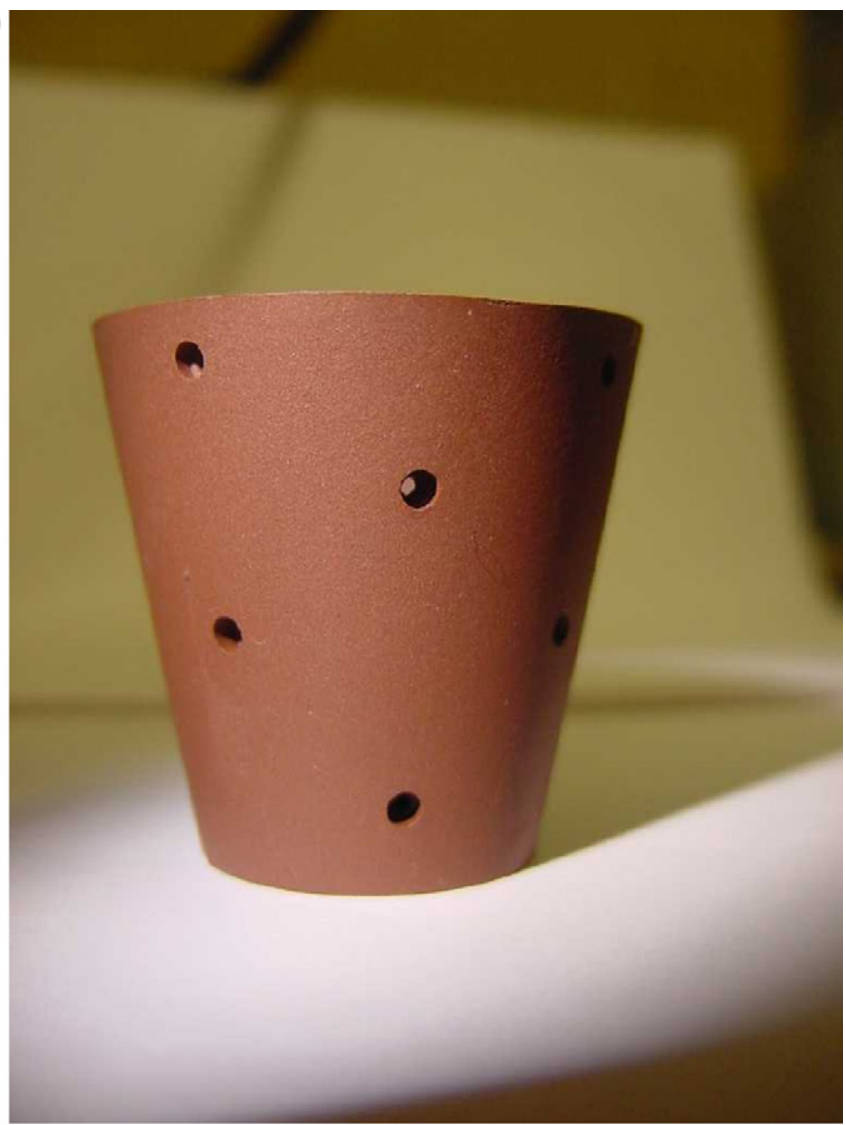

(b)

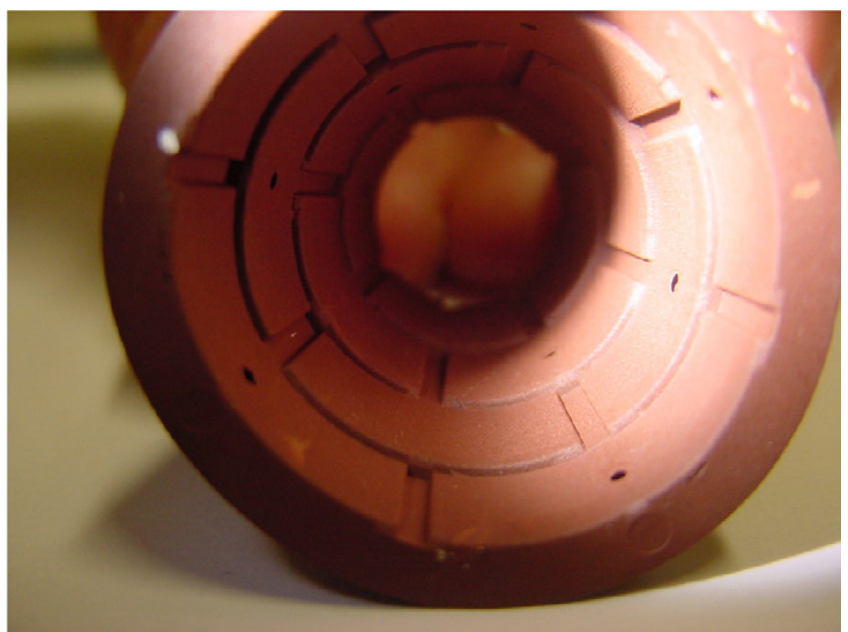

Fig. 6 - Products of calcined powder with complex geometry: (a) exterior aspect of the part after sintering; (b) interior aspect of the part after sintering.

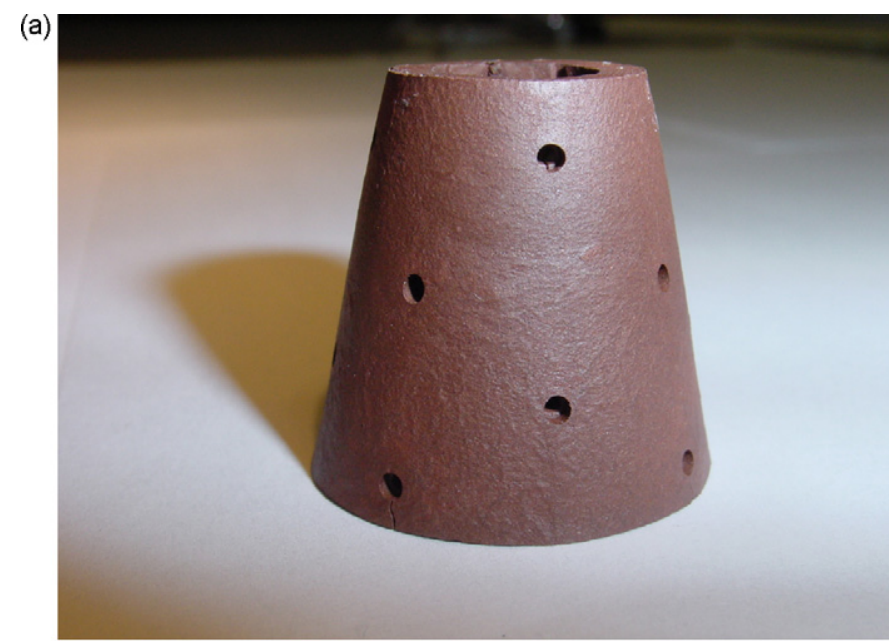

(b)

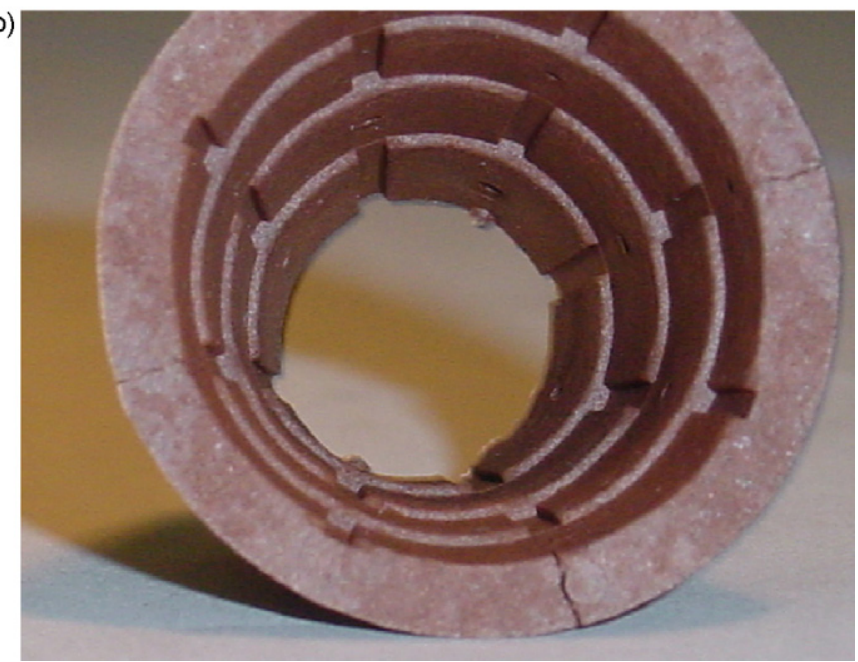

Fig. 7 - Products of non-calcined powder with complex geometry: (a) exterior aspect of the part after sintering; (b) interior aspect of the part after sintering.

The values of the flexural strength and Weibull modulus ( $\sigma_{0}=111 \mathrm{MPa}$ and $m=10$ ) obtained for bars injection-moulded with the calcined feedstock reflect the good performance of the calcined powder in the manufacturing of PIM products. The reproducibility of the flexural strength values was confirmed by a Weibull statistic - the Weibull modulus. The Weibull modulus of 10 obtained for the sintered bars should be highlighted because it corresponds to the minimum value to be considered a technical ceramic. The mechanical properties of the calcined products were slightly superior to those of the non-calcined products manufactured by PIM $\left(\sigma_{0}=93 \mathrm{MPa}\right)$ and those manufactured by a conventional shape-forming process - uniaxial pressing followed by sintering ( $\sigma_{0}=92 \mathrm{MPa}$ ) (Vieira et al., 1999; Barreiros and Vieira, 2006).

Finally, the calcined feedstock led to the absence of defects in the sintered bars; in particular, they exhibited a good surface finishing, contrary to the bars of non-calcined feedstocks that presented an irregular surface finishing, due to the chemical reactions and structural phase evolutions dur- 
Table 3 - Characteristics of the products with complex geometry of calcined and non-calcined powders after sintering

\begin{tabular}{lccc} 
Complex parts & $\rho_{\text {apps }}\left(\mathrm{kg} \mathrm{m}^{-3}\right)$ & $\rho_{\mathrm{s}}\left(\mathrm{kg} \mathrm{m}^{-3}\right)$ & $P_{\text {total }}{ }^{\mathrm{a}}(\%)$ \\
\hline Calcined powder & $2570 \pm 11$ & $2580 \pm 1$ & $1.2 \pm 0.4$ \\
$\begin{array}{l}\text { Non-calcined } \\
\text { powder }\end{array}$ & $2520 \pm 21$ & $2590 \pm 2$ & $3.1 \pm 0.8$ \\
\multicolumn{3}{c}{ a } \\
\hline Theoretical density of sintered powder $=2600 \pm 1 \mathrm{~kg} \mathrm{~m}^{-3}$.
\end{tabular}

ing sintering. Therefore, it is demonstrated that the previous heat treatments performed in the powder (which gave rise to irreversible phase transformations and, consequently, to a stable raw material) eliminated the bad surface finishing observed in the products conformed using the non-calcined feedstock. This conclusion is straightforward for the complex parts when comparing the surface aspect of the sintered parts obtained using calcined and non-calcined feedstocks (Figs. 6 and 7).

\subsubsection{Complex parts}

For the sintered complex parts, the apparent and true densities and the total porosity were measured (Table 3). The values were identical to those obtained with the sintered bars. However, for complex parts obtained from the non-calcined feedstock, the porosity was higher (Table 3) due to the increase of the surface defects and some cracks.

The complex products injection-moulded with the calcined feedstock presented a good surface finishing after sintering. These products have a smooth surface without any kind of defects (Fig. 6(a) and (b)). On the contrary, the products of the non-calcined feedstock (Fig. 7(a) and (b)) present an irregular surface finishing, which was mainly due to the blustering from the chemical reactions with gas liberation and phase transformations of the natural powder with temperature during the thermal process. Furthermore, it is also possible to observe some cracks in the bottom of the part, which begin in the outside part of the holes, and were the result of residual stresses. Thus, if phase transformations occur in an inorganic natural powder with temperature, the powder must be previously calcined to obtain the quality required for PIM parts.

\section{Conclusions}

The main conclusions of this research are:

- the calcination of the inorganic natural powders eliminated the occurrence of chemical reactions and phase transformations with temperature;

- the values of relative density (98.8\%), flexural strength (111 MPa) and Weibull modulus (10) obtained for the sintered bars of calcined powder showed the excellent performance of the calcined powder feedstock;

- finally, it was shown that the chemical reactions and phase transformations of inorganic powders during PIM were the main responsible for the irregular surface finishing observed in the final products of non-calcined powders.

\section{REFERENCES}

Agote, I., Odriozola, A., Gutierrez, M., Santamaría, A., Quintanilla, J., Coupelle, P., Soares, J., 2001. Rheological study of waste porcelain feedstocks for injection moulding. J. Eur. Ceram. Soc. 21, 2843-2853.

Barreiros, F.M., Vieira, M.T., 2000. Recovery of inorganic wastes by PIM. In: Proceedings of the 2nd European Symposium on Powder Injection Moulding (EURO PM2000), pp. 245-251.

Barreiros, F.M., Vieira, M.T., 2006. PIM of non-conventional particles. Ceram. Int. 32, 297-302.

Barreiros, F.M., Vieira, M.T., Terpstra, R.A., 2000. Performing new techniques for optimise ceramic:binder mixtures for CIM. In: Proceedings of 1st International Conference on Advanced Materials Processing, pp. 113-119.

Barreiros, F.M., Vieira, M.T., Terpstra, R.A., 2002. Optimising ceramic feedstock to injection moulding. Key Eng. Mater. 206-213, 281-284.

German, R.M., Bose, A., 1997. Injection Molding of Metals and Ceramics. Metal Powder Industries Federation, Princeton, NJ.

Haupt, U., 1996. Injection molding of porcelain. Ceram. Eng. Sci. Proc. 17 (1), 99-101.

Mutsuddy, B.C., Ford, R.G., 1995. Ceramic Injection Molding. Chapman \& Hall, London.

Vieira, M.T., Catarino, L., Oliveira, M., Sousa, J., Torralba, J.M., Cambronero, L.E.G., González-Mesones, F.L., Victoria, A., 1999. Optimization of the sintering process of raw material wastes. J. Mater. Process. Technol. 92/93, 97-101. 